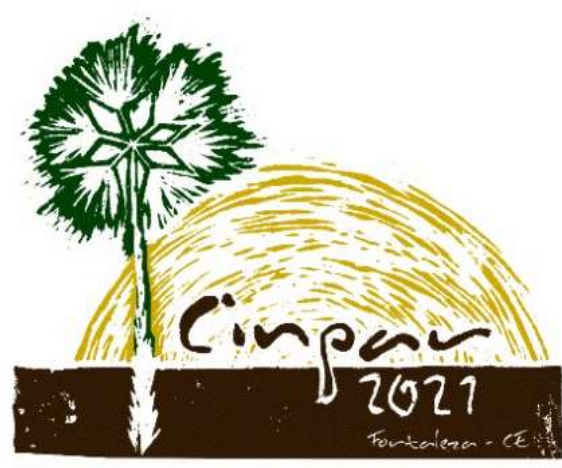

XVII Congresso Internacional sobre Patologia e Reabilitação das Construções

XVII Congreso Internacional sobre Patología y Rehabilitación de las Construcciones

XVII International Conference on Pathology and Constructions Rehabilitation

FORTALEZA (Brasil), 3 a 5 de junho de 2021 https://doi.org/10.4322/CINPAR.2021.033

\title{
ANÁLISE DO ESTADO DE CONSERVAÇÃO DE VIADUTOS NA CIDADE DE TERESINA-PI UTILIZANDO A METODOLOGIA GDE/UNB
}

\section{ANALYSIS OF VIADUCTS CONSERVATION STATUS IN TERESINA-PI CITY USING GDE / UNB METHODOLOGY}

\author{
Hygor Fernando Coimbra de Sepúlvida ${ }^{1}$, Rondinelle Marinho Monte ${ }^{2}$, Wallison Carlos de Sousa Barbosa ${ }^{3}$ \\ ${ }^{1}$ Universidade Federal do Piauí, Teresina, Brasil, hygorfernando.coimbra@gmail.com; \\ 2 Universidade Federal do Piauí, Teresina, Brasil, rondinellemarinho@gmail.com; \\ ${ }^{3}$ Universidade Federal do Piauí, Teresina, Brasil, Brasil, wallcsb@ufpi.edu.br.
}

\section{Resumo}

Este trabalho tem como objetivo apresentar dados a respeito do estado de conservação de alguns viadutos da cidade de Teresina-PI, apresentando as principais manifestações patológicas existentes nessas estruturas. A metodologia empregada neste trabalho foi a metodologia GDE/UnB. Essa metodologia preconiza a divisão da estrutura em famílias de elementos e, como resultado, permite que se calcule o Grau de Deterioração dessa Estrutura $\left(G_{d}\right)$. A realização prévia de inspeções visuais nas estruturas é imprescindível para a aplicação da metodologia GDE/UnB. Após o cálculo do valor de "G ${ }_{d}$ ", procedeu-se à classificação dessa estrutura de acordo com o nível de deterioração verificado.

Palavras-chave: patologia, Grau de Deterioração da Estrutura, Viadutos.

\begin{abstract}
This work aims to present data about the state of conservation of some viaducts in the city of Teresina-PI, presenting the main pathological manifestations existing in these structures. The methodology used in this work was the GDE / UnB methodology. This methodology recommends the division of the structure into families of elements and, as a result, allows the calculation of the Degree of Deterioration of this Structure (Gd). The prior performance of visual inspections on the structures is essential for the application of the GDE / UnB methodology. After calculating the "Gd" value, this structure was classified according to the level of deterioration found.
\end{abstract}

Keywords: pathology, Degree of Structure Deterioration, Viaducts. 


\section{Introdução}

As Obras de Arte Especiais (OAEs), compostas de pontes, viadutos, passarelas e túneis, são fundamentais para que se implemente uma eficiente infraestrutura rodoviária e ferroviária em uma localidade. Na cidade de Teresina-PI, que é uma cidade cortada pelo rio Poti e que, além disso, possui o rio Parnaiba que a separa do município de Timon-MA, as OAEs apresentam-se como estruturas funcionais, partindo-se do fato de que são imprescindíveis para conectar as diferentes partes da cidade separadas pelo rio Poti e, ainda, para interligar a cidade, por meio do rio Parnaiba, ao município de Timon-MA. Além disso, essas estruturas são fundamentais para se conectar as mais diversas vias dentro do seu perímetro urbano.

A quantidade e/ou gravidade das manifestações patológicas em estruturas têm impacto direto em seus respectivos custos de manutenção. Esse fato pode ser verificado quando do planejamento das manutenções nessas estruturas, já que, segundo Mattos (2010), quando da avaliação dos custos envolvidos na prevenção de manifestações patológicas em diferentes fases de uma dada obra, observa-se que quanto mais tarde se dá a detecção desses problemas, maiores serão seus respectivos custos de reparo. Por essa razão, alguns estudos têm sido feitos no sentido de mapear essas manifestações patológicas e, a partir dos dados assim levantados, processar essas informações de forma a disponibilizar meios adequados de correções que venham a restaurar as condições normais de utilização dessas estruturas. 0 emprego das correções, porém, não se constitui na única forma de atuação no sentido de se implementar as atividades de conservação dessas estruturas. Segundo a FWHA (2011), as atividades de conservação a serem implementadas nas OAEs podem ser divididas em: substituição, reabilitação e manutenção. Essas atividades devem, necessariamente, ser baseadas em procedimentos de inspeção adequados a cada tipo de situação.

Os objetivos gerais deste trabalho são avaliar o estado de conservação de alguns viadutos, localizados na cidade de Teresina-PI e recomendar ações a serem adotadas em função do estado de conservação de cada viaduto inspecionado.

Já os objetivos específicos deste trabalho são: selecionar 5 (cinco) viadutos localizados na cidade de TeresinaPI; aplicar a metodologia Grau de Deterioração da Estrutura (GDE/UnB) a cada viaduto selecionado; e classificar os estados de conservação das estruturas inspecionadas de acordo com as notas técnicas obtidas por meio da metodologia GDE/UnB.

\subsection{Metodologia}

A metodologia empregada neste trabalho seguiu a sequência de atividades abaixo descritas:

- Seleção dos viadutos para inspeção:

Procurou-se selecionar, por meio de inspeção visual, os viadutos que apresentassem as maiores quantidades de manifestações patológicas e, também, os que apresentassem as anomalias mais graves. Neste cenário, os seguintes viadutos foram selecionados:

1) viaduto do bairro Lourival Parente;

2) viaduto ferroviário sobre a rua Goiás;

3) viaduto ferroviário do CFAP (Centro de Formação e Aperfeiçoamento de Praças);

4) viaduto da Rodoviária 01;

5) viaduto da Rodoviária 02;

- Procedimentos de inspeção:

A equipe empregada para a execução das inspeções foi composta de dois engenheiros civis. Após a devida seleção das OAEs, a equipe se deslocou até os respectivos locais, portando os seguintes equipamentos:

- câmera fotográfica digital;

- prancheta para elaboração de croquis e demais anotações.

O objetivo das inspeções foi basicamente fazer registros fotográficos da estrutura como um todo e de cada um dos seus respectivos elementos estruturais. A utilização de registros fotográficos foi contemplada como um dos procedimentos de inspeção listados na ABNT NBR 9452 (2016).

- Análise dos dados e categorização dos elementos estruturais:

A partir dos dados levantados durante as inspeções, procedeu-se a uma categorização dos elementos estruturais das OAEs em diversas famílias de elementos estruturais. 
- Resultados:

Após a fase de inspeções das OAEs, as estruturas foram analisadas segundo a metodologia GDE/UnB que, como resultado, gerou o Grau de Deterioração da Estrutura $\left(G_{d}\right)$. Em seguida, de acordo com o valor de $G_{d}$ obtido para cada OAE inspecionada, procedeu-se à uma classificação dos estados de conservação de cada estrutura. Essa classificação, proposta por Verly (2015), indica, também, as ações a serem adotadas de acordo com a nota técnica obtida por meio da aplicação da metodologia GDE/UnB.

\section{Aplicação da metodologia GDE/UnB em viadutos de Teresina-PI}

Neste trabalho foram analisados cinco viadutos, localizados na cidade de Teresina-PI (Figura 1).

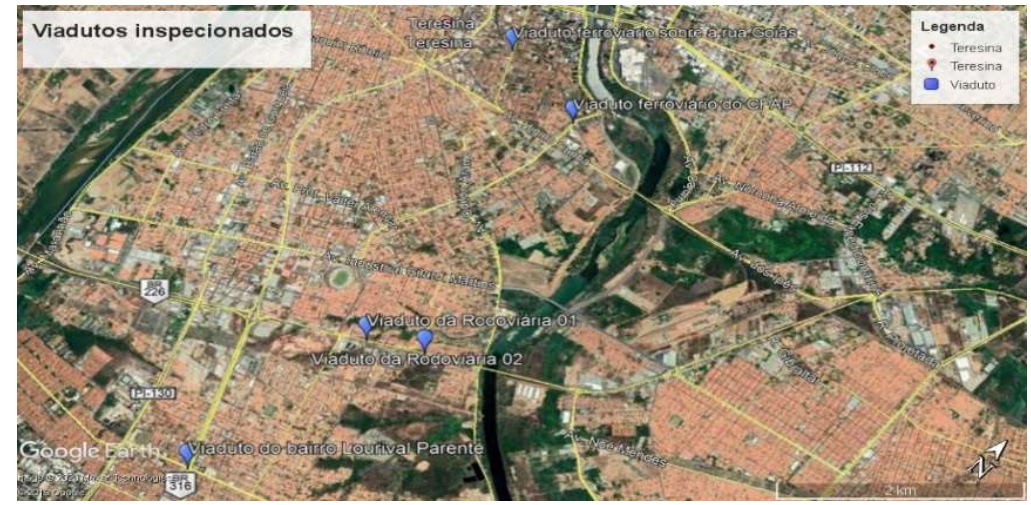

Figura 1 - Localização dos viadutos analisados neste trabalho

A seguir, tem-se a análise de cada uma dessas estruturas:

\section{- Viaduto do bairro Lourival Parente (Figuras 2 e 3):}

Ficha técnica:

- Localização: rodovia BR 316, cruzamento entre a rua Ivan Tito de Oliveira e a avenida Prefeito Wall Ferraz;

- Tipo de transposição: viaduto sobre rodovia;

- Classe de agressividade ambiental - ABNT NBR 6118 (2014): classe II.

- Coordenadas geográficas:

- Latitude: -5.135910;

- Longitude: -42.789415 ㅇ.

- Dados de projeto:

- Comprimento do viaduto: 40,00 m;

- Largura do viaduto: $20,00 \mathrm{~m}$.
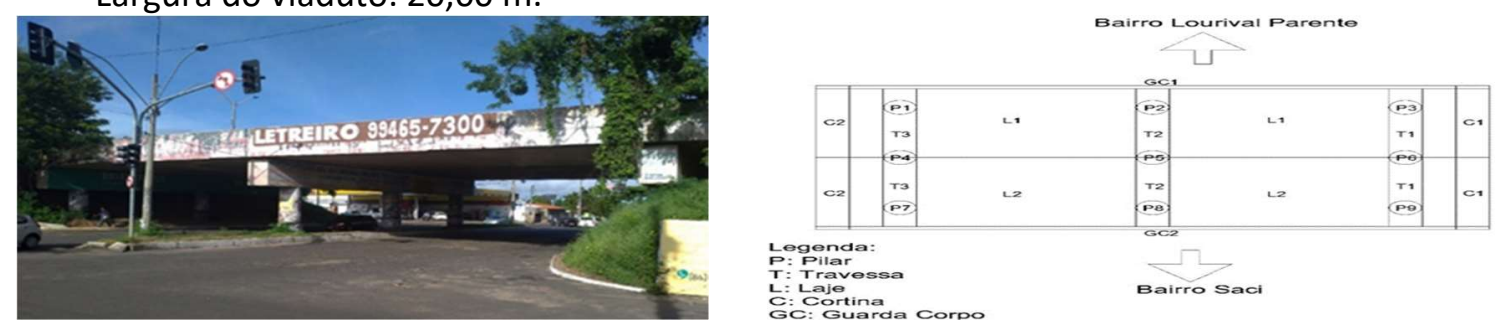

Figura 2 - Viaduto do bairro Lourival Parente

Figura 3 - Croqui referente ao viaduto do Bairro Lourival Parente

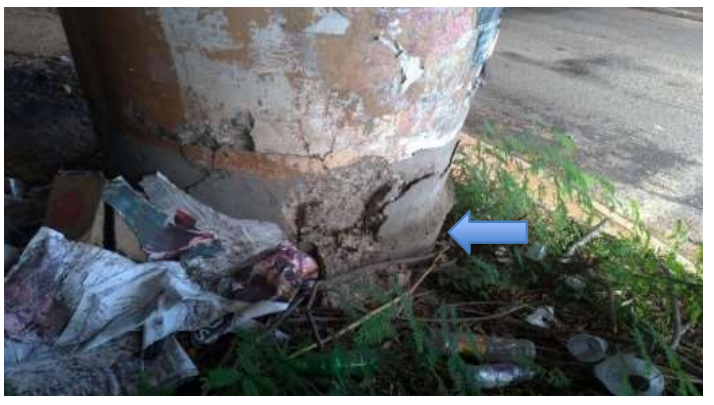

(a)

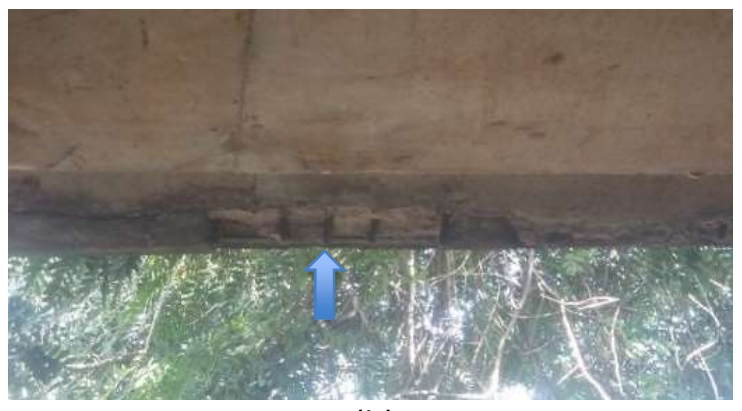

(b) 


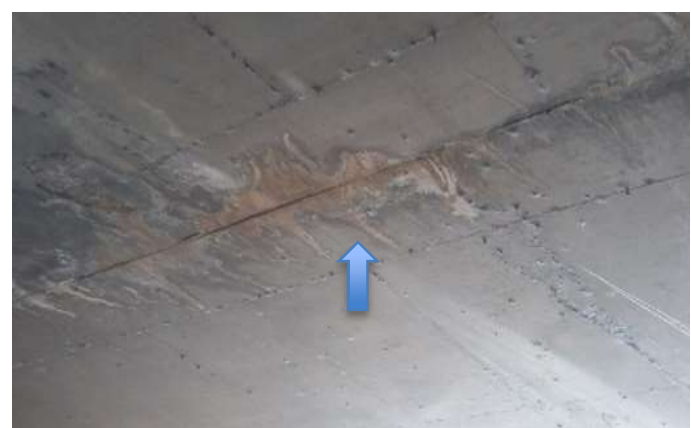

(c)

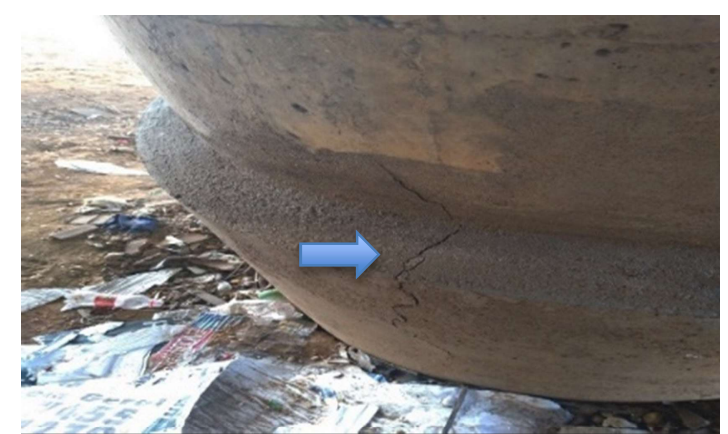

(d)

Figura 4 - Manifestações patológicas verificadas na estrutura. (a) desplacamento do concreto da estrutura; (b) corrosão de armaduras; (c) eflorescência; (d) fissura em pilar da estrutura

\section{- Viaduto ferroviário sobre a rua Goiás (Figuras 5 e 6):}

Ficha técnica:

○ Localização: rua Goiás, no 654, bairro Ilhotas;

- Tipo de transposição: viaduto ferroviário sobre rodovia;

- Classe de agressividade ambiental - ABNT NBR 6118 (2014): classe II.

- Coordenadas geográficas:

- Latitude: -5.0902240;

- Longitude: -42.7978840.

- Dados de projeto:

- Comprimento do viaduto: 35,00 m;

- Largura do viaduto: $18,00 \mathrm{~m}$.

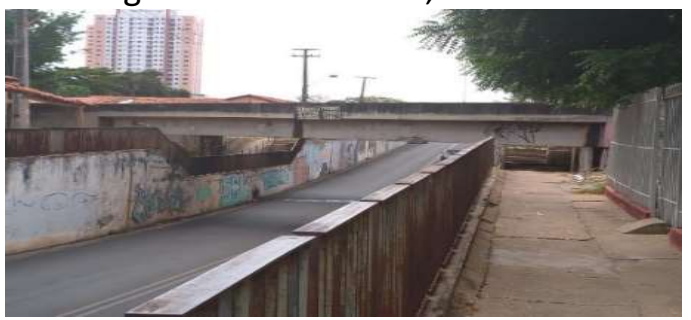

Figura 5 - Viaduto ferroviário sobre a rua Goiás

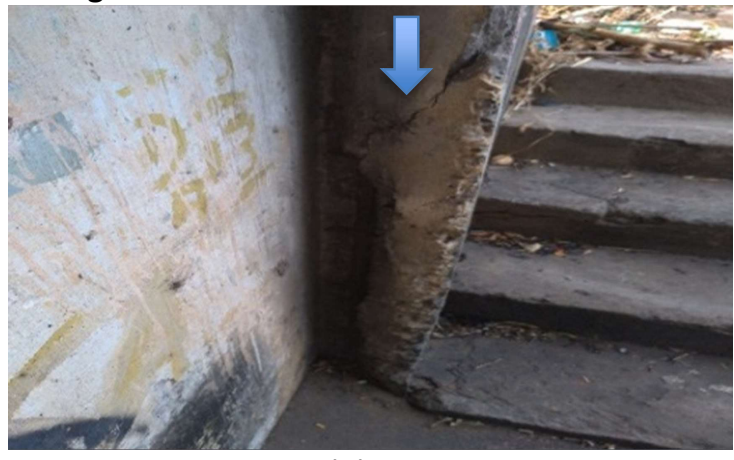

(a)

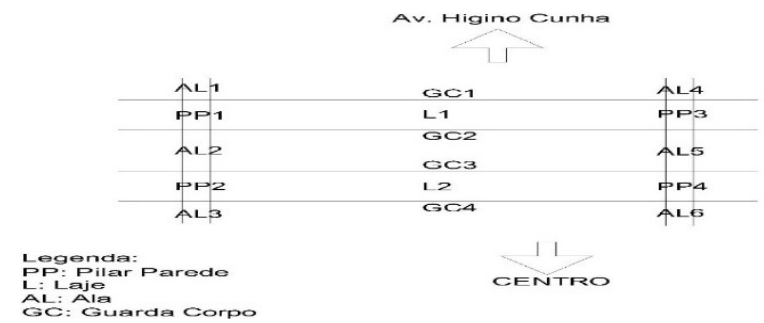

Figura 6 - Croqui referente ao viaduto da rua Goiás

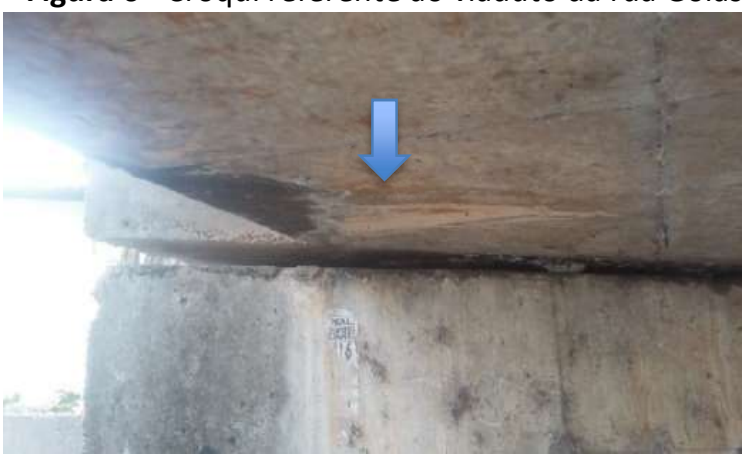

(b)

Figura 7 - Manifestações patológicas verificadas na estrutura. (a) desplacamento de concreto da estrutura; (b) eflorescência

\section{- Viaduto ferroviário do CFAP (Figura 8 e 9):}

Ficha técnica:

- Localização: avenida Marechal Castelo Branco, no 201, bairro Cabral;

- Tipo de transposição: viaduto ferroviário sobre rodovia;

- Classe de agressividade ambiental - ABNT NBR 6118 (2014): classe II.

- Coordenadas geográficas:

- Latitude: -5.0926810;

- Longitude: -42.7892210.

- Dados de projeto:

- Comprimento do viaduto: $41,00 \mathrm{~m}$; 
- Largura do viaduto: $13,00 \mathrm{~m}$.

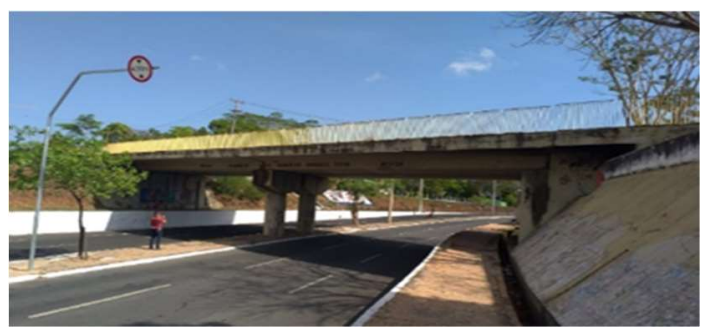

Figura 8 - Viaduto ferroviário do CFAP

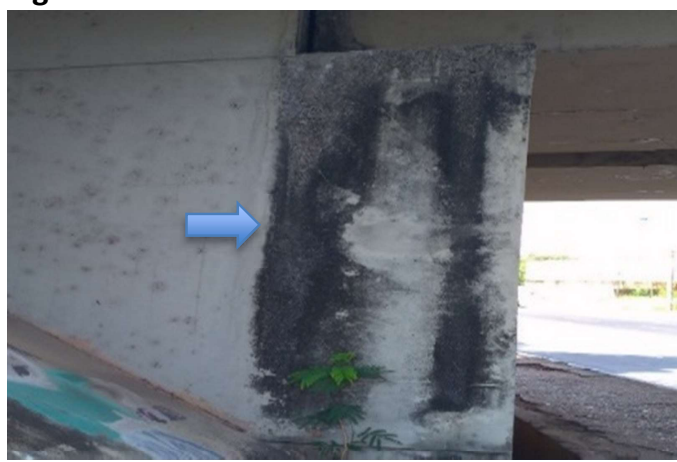

(a)

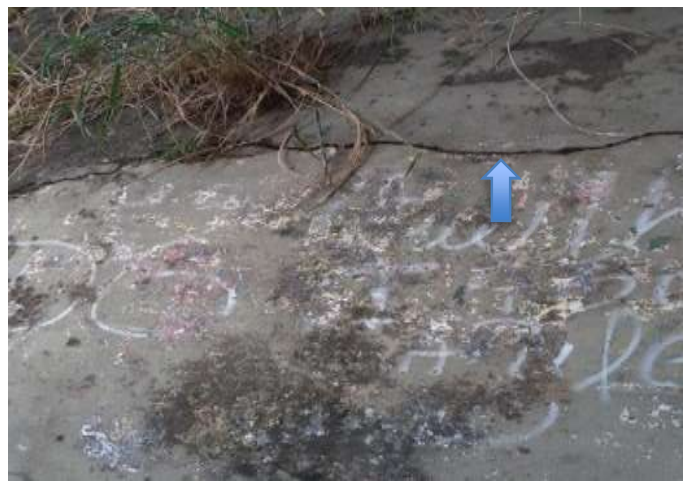

(c)

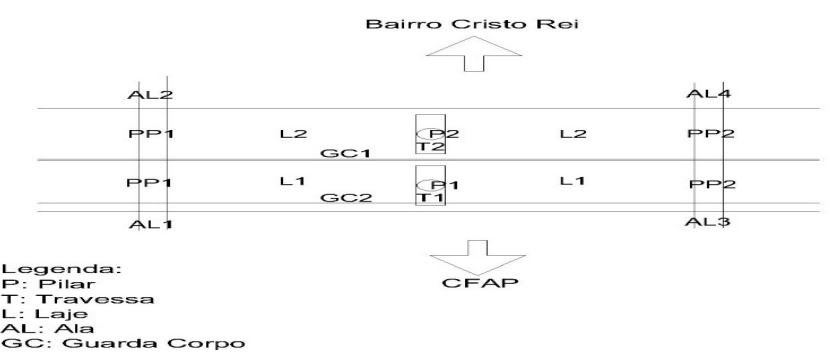

Figura 9 - Croqui referente ao viaduto do CFAP

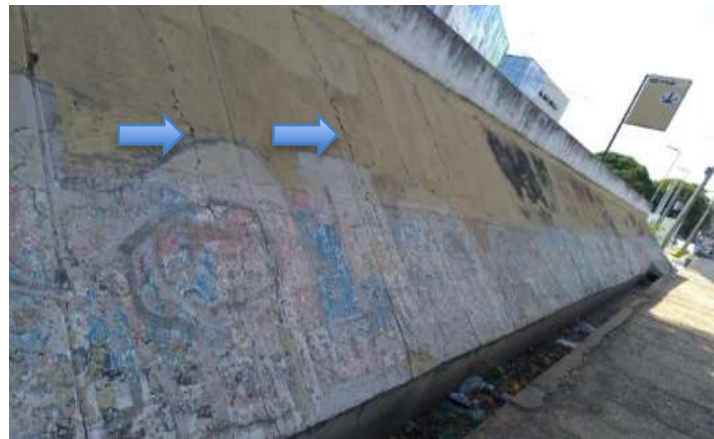

(b)

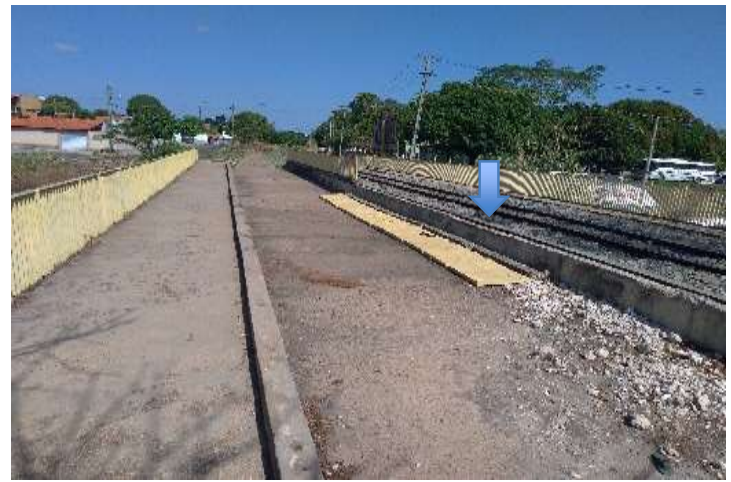

(d)

Figura 10 - Manifestações patológicas verificadas na estrutura. (a) manchas de umidade; (b) fissuras de retração no concreto; (c) fissura em elemento da estrutura; (d) desplacamento do concreto da estrutura

\section{- Viaduto da Rodoviária de Teresina 01 (Figuras 11 e 12):}

Ficha técnica:

- Localização: avenida Presidente Getúlio Vargas, no 966, bairro Santa Luzia;

- Tipo de transposição: viaduto sobre rodovia;

- Classe de agressividade ambiental - ABNT NBR 6118 (2014): classe II.

- Coordenadas geográficas:

- Latitude: -5.117076o;

- Longitude: -42.783133 .

- Dados de projeto:

- Comprimento do viaduto: $13,30 \mathrm{~m}$;

- Largura do viaduto: $12,91 \mathrm{~m}$.

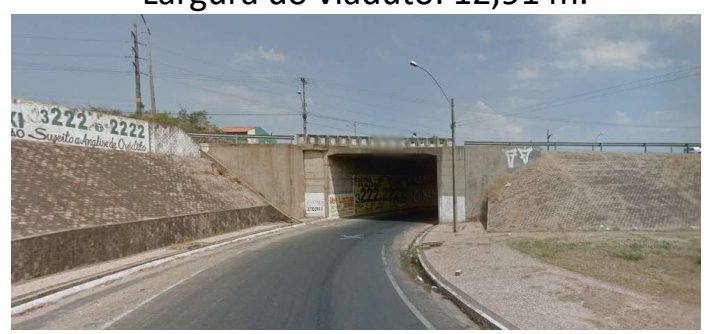

Figura 11 - Viaduto da Rodoviária de Teresina 01

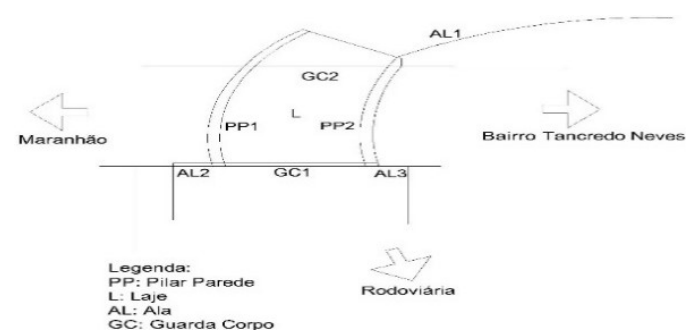

Figura 12-Croqui referente ao viaduto da Rodoviária de Teresina 01 


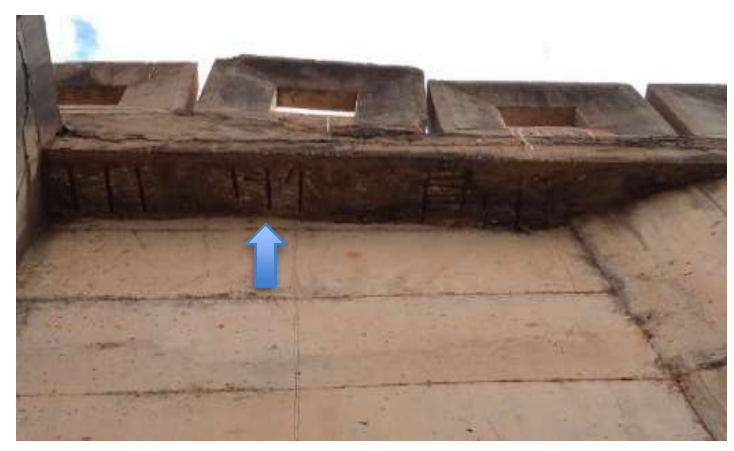

(a)

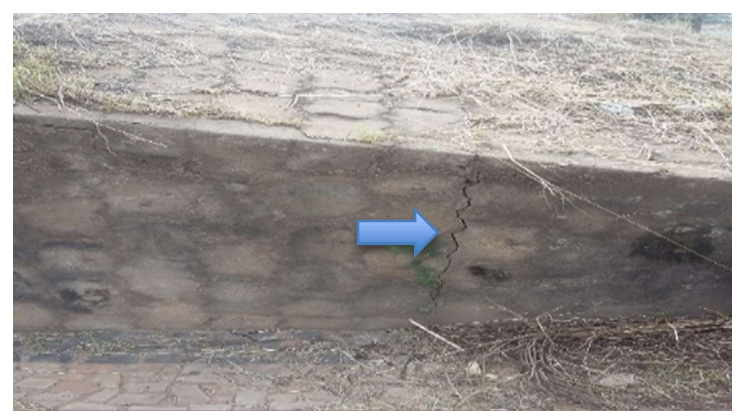

(c)

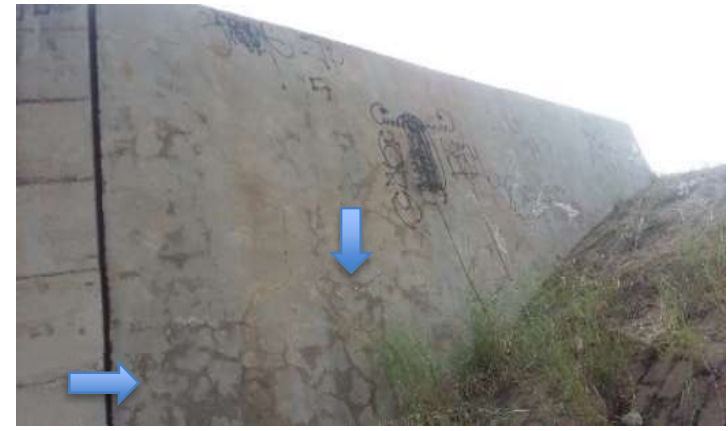

(b)

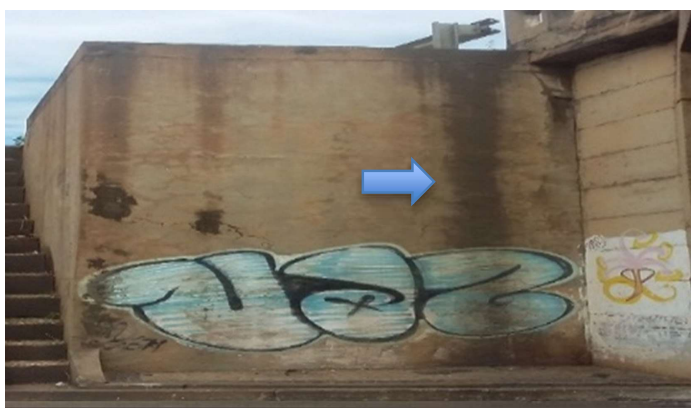

(d)

Figura 13 - Manifestações patológicas verificadas na estrutura. (a) desplacamento na estrutura; (b) fissura por reação expansiva endógena no concreto; (c) fissura em elemento da estrutura; (d) manchas de umidade

- Viaduto da Rodoviária de Teresina 02 (Figuras 14 e 15):

Ficha técnica:

- Localização: rodovia BR 343, no 496;

- Tipo de transposição: viaduto sobre rodovia;

- Classe de agressividade ambiental - ABNT NBR 6118 (2014): classe II.

- Coordenadas geográficas:

- Latitude: -5.1190710;

- Longitude: -42.787309 .

- Dados de projeto:

- Comprimento do viaduto: $26,00 \mathrm{~m}$;

- Largura do viaduto: $15,00 \mathrm{~m}$.
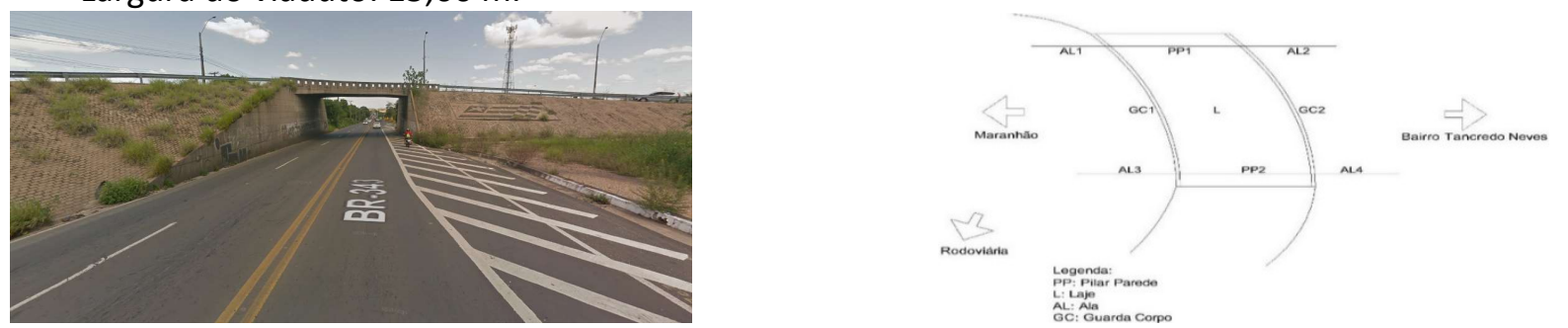

Figura 14 - Viaduto da Rodoviária de Teresina 02

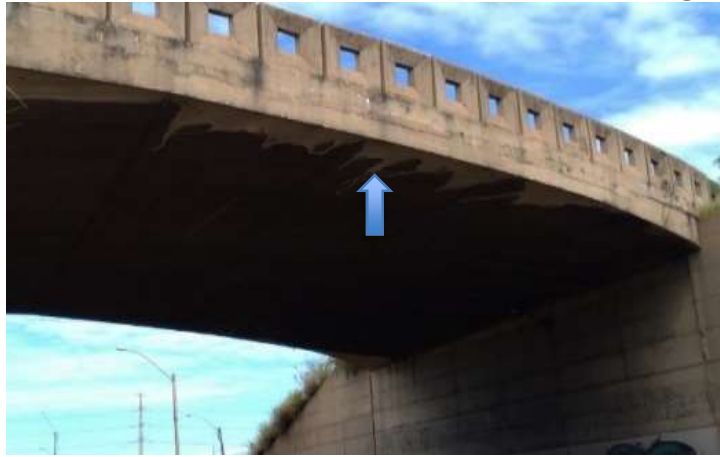

(a)

Figura 15-Croqui referente ao viaduto da Rodoviária de Teresina 02

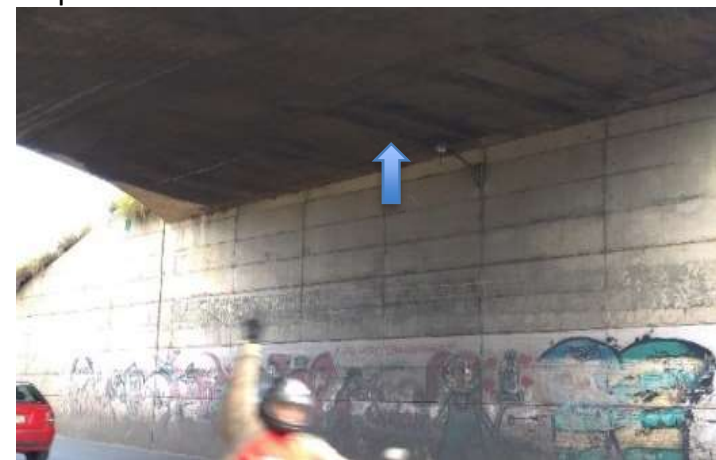

(b)

Figura 16 - Manifestações patológicas verificadas na estrutura. (a) eflorescência; (b) manchas de umidade 


\section{Resultados e discussões}

Nesta seção, foi realizada uma comparação dos valores do Grau de Deterioração da Família de Elementos $\left(G_{\mathrm{df}}\right)$ verificados nos principais elementos de cada viaduto analisado.

\section{○ Pilares:}

Os pilares do viaduto do bairro Lourival Parente apresentaram um nível de deterioração sofrível $\left(G_{d f}=86,65\right)$, sendo que devem ser realizadas inspeções rigorosas, planejando-se intervenções em curto prazo (máximo de 6 meses). Os pilares do viaduto da rua Goiás apresentaram um nível de deterioração médio $\left(G_{d f}=46,08\right)$, sendo necessário definir um prazo e a natureza de uma nova inspeção, planejando-se as intervenções em um longo prazo (máximo de 2 anos). Já os pilares referentes aos viadutos do CFAP, da Rodoviária de Teresina 01 e 02, apresentaram um baixo nível de deterioração, sendo necessários somente a execução de manutenções preventivas, já que seus respectivos estados de conservação são considerados aceitáveis.

\section{- Travessas:}

As travessas do viaduto do bairro Lourival Parente apresentaram um nível de deterioração médio $\left(G_{d f}=\right.$ $25,19)$, sendo necessário definir um prazo e a natureza de uma nova inspeção, planejando-se as intervenções em um longo prazo (máximo de 2 anos). Já as travessas do viaduto do CFAP apresentaram um baixo nível de deterioração $\left(G_{d f}=8,82\right)$, sendo necessários somente a execução de manutenções preventivas, já que seus respectivos estados de conservação são considerados aceitáveis.

\section{o Cortinas:}

As cortinas do viaduto do bairro Lourival Parente apresentaram um nível de deterioração alto $\left(G_{d f}=77,48\right)$, sendo que devem ser realizadas inspeções especializadas no local, planejando-se intervenções em médio prazo (máximo de 1 ano).

\section{○ Alas:}

As alas dos viadutos do CFAP e da Rodoviária de Teresina 01 apresentaram níveis de deterioração médio $\left(\mathrm{G}_{\mathrm{df}}\right.$ $=21,17$ e $G_{\text {df }}=23,70$, respectivamente), sendo necessário definir um prazo e a natureza de novas inspeções, planejando-se as intervenções em um longo prazo (máximo de 2 anos). Já as alas referentes aos viadutos da rua Goiás e da Rodoviária de Teresina 02, apresentaram baixos níveis de deterioração $\left(G_{d f}=6,20\right.$ e $G_{d f}=0$, respectivamente), sendo necessários somente a execução de manutenções preventivas, já que seus respectivos estados de conservação são considerados aceitáveis. $\mathrm{O}$ viaduto do bairro Lourival Parente não possui o elemento ala em sua estrutura.

\section{○ Lajes:}

As lajes dos viadutos do bairro Lourival Parente e da Rodoviária de Teresina 02 apresentaram níveis de deterioração médio ( $G_{\mathrm{df}}=46,54$ e $G_{\mathrm{df}}=26,82$, respectivamente), sendo necessário definir um prazo e a natureza de novas inspeções, planejando-se as intervenções em um longo prazo (máximo de 2 anos). Já as cortinas referentes aos demais viadutos, por possuírem valores de $G_{\text {df }}$ inferiores a 15 , apresentaram baixos níveis de deterioração, sendo necessário somente a execução de manutenções preventivas, já que seus respectivos estados de conservação são considerados aceitáveis.

\section{○ Barreiras:}

As barreiras dos viadutos da rua Goiás e do CFAP apresentaram altos níveis de deterioração ( $G_{d f}=50,75$ e $G_{d f}$ $=73,48$, respectivamente), sendo que devem ser realizadas inspeções especializadas no local, planejando-se intervenções em médio prazo (máximo de 1 ano). As barreiras do viaduto da Rodoviária de Teresina 01 apresentaram níveis de deterioração médio $\left(G_{d f}=36,00\right)$, sendo necessário definir um prazo e a natureza de uma nova inspeção, planejando-se as intervenções em um longo prazo (máximo de 2 anos). Já as barreiras referentes aos demais viadutos apresentaram baixos níveis de deterioração, sendo necessários somente a execução de manutenções preventivas, já que seus respectivos estados de conservação são considerados aceitáveis.

O gráfico da Figura 17 ilustra a variação dos valores de $G_{\text {df }}$ para os principais elementos da estrutura dos viadutos estudados neste trabalho. 


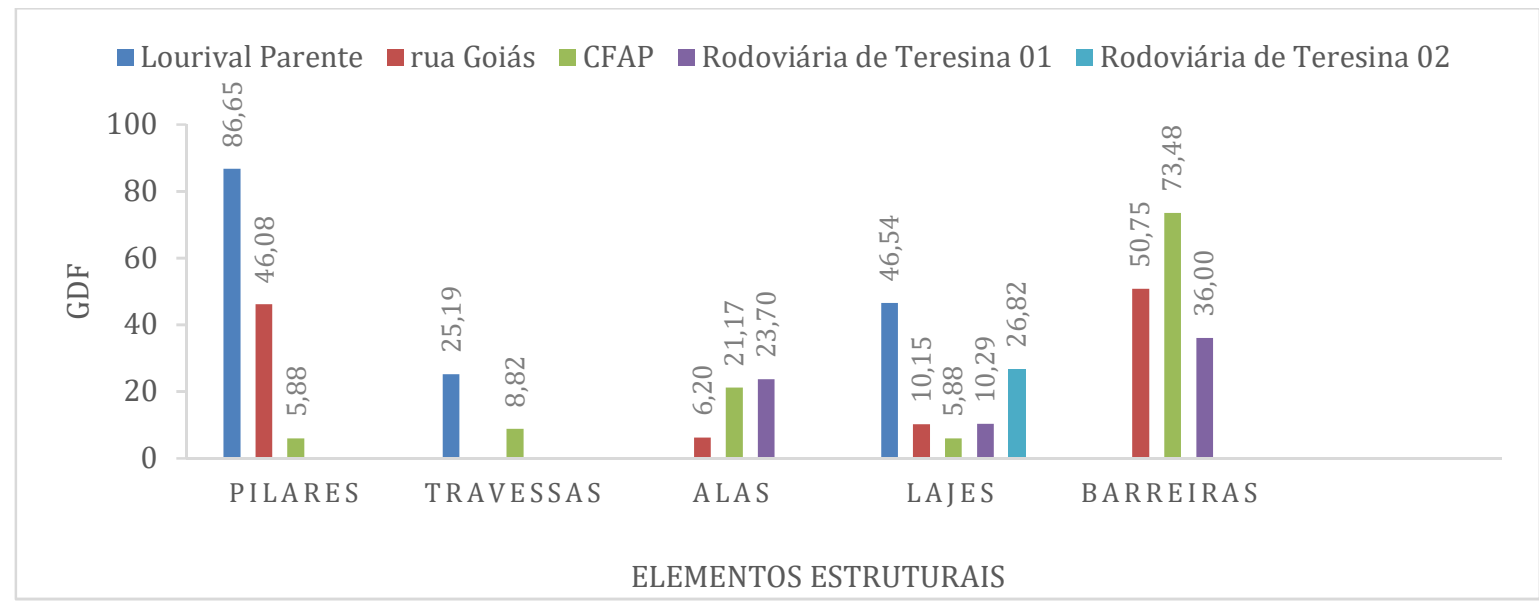

Figura 17 - Variação dos valores de Gdf dos elementos de cada viaduto analisado

Os valores do Grau de Deterioração da Estrutura $\left(G_{d}\right)$ encontrados foram:

- Viaduto do bairro Lourival Parente: $G_{d}=77,45$;

- Viaduto ferroviário sobre a rua Goiás: $G_{d}=37,48$;

- Viaduto ferroviário do CFAP: $\mathrm{G}_{\mathrm{d}}=13,50$;

- Viaduto da Rodoviária de Teresina 01: $\mathrm{G}_{d}=12,40$;

- Viaduto da Rodoviária de Teresina 02: $\mathrm{G}_{d}=15,18$.

\section{Conclusões}

Percebeu-se que, no tocante aos valores do Grau de Deterioração da Estrutura (Gd) encontrados, tem-se que o viaduto do bairro Lourival Parente apresentou um maior valor de $\mathrm{Gd}(\mathrm{Gd}=77,45)$, frente aos demais viadutos analisados. $\mathrm{O}$ valor de Gd verificado no viaduto do bairro Lourival Parente encontra-se no intervalo de 50 a $80(50 \leq \mathrm{Gd} \leq 80)$. Com isso, tem-se que ele se enquadra na categoria de alto grau de deterioração, o que exige um planejamento de intervenção especializada em médio prazo (máximo de um ano). $O$ viaduto ferroviário da rua Goiás apresentou um valor de Gd igual a 37,48. Isso significa que, esse viaduto se enquadra na categoria de médio nível de deterioração da estrutura e, com isso, deve-se definir um prazo e natureza de uma nova inspeção, planejando a intervenção em um longo prazo (máximo de dois anos).

O viaduto da Rodoviária de Teresina 02 apresentou um valor de Gd igual a 15,18. Esse valor de Gd é ligeiramente superior ao limite preconizado para a categoria de baixo nível de deterioração da estrutura (0 $\leq \mathrm{Gd} \leq 15$ ). Sendo assim, esse viaduto se enquadra na categoria de médio nível de deterioração da estrutura, o que exige, assim como para o viaduto ferroviário da rua Goiás, a definição de prazo e natureza de nova inspeção aliada a um planejamento de uma intervenção a longo prazo (máximo de dois anos). Finalmente, os viadutos do CFAP e da Rodoviária de Teresina 01, que apresentaram valores de Gd inferiores a 15 ( $\mathrm{Gd}=$ 13,50 e $\mathrm{Gd}=12,40$, respectivamente), devem receber apenas manutenção preventiva, sendo seus respectivos estados de conservação considerados aceitáveis.

\section{Referência Bibliográficas}

ASSOCIAÇÃO BRASILEIRA DE NORMAS TÉCNICAS. Projeto de estruturas de concreto: procedimento. NBR 6118, Rio de Janeiro, 2014.

ASSOCIAÇÃO BRASILEIRA DE NORMAS TÉCNICAS. Inspeção de pontes, viadutos e passarelas de concreto Procedimento. NBR 9452, Rio de Janeiro, 2016.

FHWA. Bridge Preservation Guide, USA, 2011, Federal Highway Administration, 32 p.

MATTOS, A. D. M. Planejamento e controle de obras, São Paulo, Pini, 1ed, 2010, 420 p.

VERLY, R. C. Avaliação de metodologias de inspeção como instrumento de priorização de intervenções em obras de arte especiais, Brasília, 2015, Dissertação de Mestrado - Departamento de Engenharia Civil e Ambiental, Faculdade de Tecnologia, Universidade de Brasília, 178 p. 